\title{
An unusual case of pycnodysostosis
}

\author{
R KUMAR, P K MISRA, AND R SINGHAL \\ Department of Paediatrics, King George's Medical College, Lucknow, India
}

SUMmaRY A 6 year old boy with clinical and radiological features of pycnodysostosis is described. In addition to pycnodysostosis he had a myelophthisic type of anaemia suggesting an overlap with osteopetrosis.

The term pycnodysostosis was coined in 1962 by Maroteux and Lamy who reported certain consistent variations in the syndromes of osteopetrosis and cleidocranial dysostosis. ${ }^{1}$ Altogether, a total of 77 cases have been described. The syndrome has been seen in individuals of many races and nationalities incuding black, Arab, and white. ${ }^{1}$ The present case, reported from Lucknow, India has certain uncommon features.

\section{Case report}

A 6 year old boy was brought to the childrens' outpatient department with complaints of a large head and protuberant eyes that had been worrying his parents over the last several months. There were no other important symptoms. He had, however, been admitted to hospital at the age of 4 months when his limbs were noted to be excessively curved. Multiple fractures of the long bones and blue sclerae had been detected at that time and he was discharged with the diagnosis of osteogenesis imperfecta. Since discharge he had remained well.

He was the third child born of a consanguineous Muslim marriage. The other siblings were normal and no other family member had repeated fractures or an abnormal facial appearance. His father had a malformed, hypoplastic pinna on one side. On examination his weight and height were $14 \mathrm{~kg}$ and 87 $\mathrm{cm}$, respectively. He was pale. The head appeared large with frontal and parietal bossing, a wide anterior fontanelle $(4 \times 4 \mathrm{~cm}$ in size) and open cranial sutures. The eyes were protuberant and sclerae appeared blue. Fundus examination was normal. The hands were short and broad with dystrophic nails. There was bilateral anterior bowing of the tibiae. The liver and spleen were felt $4 \mathrm{~cm}$ and $2.5 \mathrm{~cm}$ below the costal margin, respectively.

Investigations showed a normocytic, normochromic anaemia with a haemoglobin of $55 \mathrm{~g} / \mathrm{l}$ on admission. Reticulocyte count was $2 \%$. Serum calcium and phosphorus concentrations and alkaline phosphatase activity were within normal limits. Radiographs showed a generalised increase in bone density. The skull showed wide open anterior fontanelle and sutures, especially the parietooccipital. The mandibular angle was obtuse so as to be almost obliterated. Metaphyseal striations in the long bones were not seen. The distal phalanges of the fingers were tapering with absence of the ungual tufts. Bone marrow aspirate was difficult to obtain because of hard bone that was difficult to pierce but a trephine biopsy specimen showed few bony trabeculae and a fibrosed marrow space. A computed tomogram of the head gave a normal result.

\section{Discussion}

Pycnodysostosis may be recognised at any age from infancy to adulthood. Clinical features are short stature at all ages, fractures, large head with frontal and parietal bossing, open anterior fontanelle and cranial sutures, obtuse mandibular angle, prominent eyes with bluish sclerae, underdeveloped facial bones, persistence of deciduous teeth into adulthood often with caries, short, broad hands and feet with dystrophic nails and trunk deformities such as kyphosis, scoliosis, increased lumbar lordosis, and narrow chest. ${ }^{2}$

Laboratory investigations usually give results within normal limits. Raised plasma calcitonin concentrations have been reported, however. ${ }^{3}$ A generalised increase in bone density is seen on radiographs, but medullary canals are evident. Some degree of widening of the distal femur may be seen. The skull shows open anterior fontanelle and sutures with small facial bones, non-pneumatised paranasal sinuses and a flattened mandibular angle. A wormian bone pattern may be seen in the parietal bone. Terminal phalanges in the hand are partially or totally aplastic with loss of ungual tufts. The acromial ends of the clavicles may also be aplastic. Other abnormalities include failure of complete segmentation of the atlas, axis, and the lower lumbar spine, coxa valga and abnormal radioulnar articulation. ${ }^{1}$ Histologically, the appearance is similar to that of osteopetrosis but the medullary canals are present and microscopic evidence of 
haemopoiesis. A dynamic study of tetracycline uptake led to the conclusion that there is a slowing down of bone resorption and formation. ${ }^{4}$

An autosomal recessive pattern of inheritance of pycnodysostosis is suggested. Elmore $e t$ al reported a deletion of the short arm of chromosome 22 in a patient and several unaffected family members. ${ }^{5}$ This suggests the possibility that the gene is located on the short arm of this chromosome and that it manifested itself in the hemizygote state in this patient.

Features which differentiate osteopetrosis (AlbersSchönberg disease) from pycnodysostosis are normal stature, cranial nerve compression, myelophthisic anaemia, osteitis, non-differentiation of cortex from medulla in long bones, more severe modelling defect, and an appearance of alternate radiodense and lucent bands (striations) near the metaphyseal ends of long bones in the former. Biochemical abnormalities such as raised serum alkaline phosphatase activity are also seen. Skull dysplasia, blue sclerae, and hypoplasia of the distal phalanges are not commonly reported with osteopetrosis. ${ }^{1}$

The patient described here had the clinical and radiological features of pycnodysostosis. In addition he had a myelophthisic anaemia with hepatosplenomegaly, which is not commonly reported in this disorder and in fact is held to be a differentiating feature separating it from osteopetrosis. ${ }^{1}$ Similar cases have, however, been reported. ${ }^{6}$ The disorders osteopetrosis and pycnodysostosis may represent the two ends of a spectrum, so that an occasional patient has overlapping manifestations of both. This patient therefore reinforces the belief that a close relation exists between these disorders.

\section{References}

1 Elmore SM. Pycnodysostosis: a review. J Bone Joint Surg [Am] 1967;49:153-61.

${ }^{2}$ Maroteaux P. The osteochondrodysplasias. In: Maroteaux P, ed. Bone diseases of children. Philadelphia: JB Lippincott Co, 1979:116.

${ }^{3}$ Baker RK, Wallach S, Tashjian AH. Plasma calcitonin in pycnodysostosis: intermittently high basal levels and exaggerated response to calcium and glucagon infusion. Journal of Clinical Endocrinology 1973;37:46-55.

${ }^{4}$ Sarn Sethsiri P, Hitt OK, Eyring EJ. Frost HM. Tetracycline based study of bone dynamics in pycnodysostosis. Clin Orthop 1971;74:301-12.

5 Elmore SM, Nance WE, McGee BJ, et al. Pycnodysostosis with a familial chromosome anomaly. Am J Med 1966;40:273-82.

${ }^{6}$ Kozlwski K, Yu JS. Pycnodysostosis: a variant form with visceral manifestations. Arch Dis Child 1972;47:804-7.

Correspondence to Dr R Kumar, 33 Usman Enclave, Aliganj Extension, Lucknow 226020 , India.

Accepted 22 December 1987 